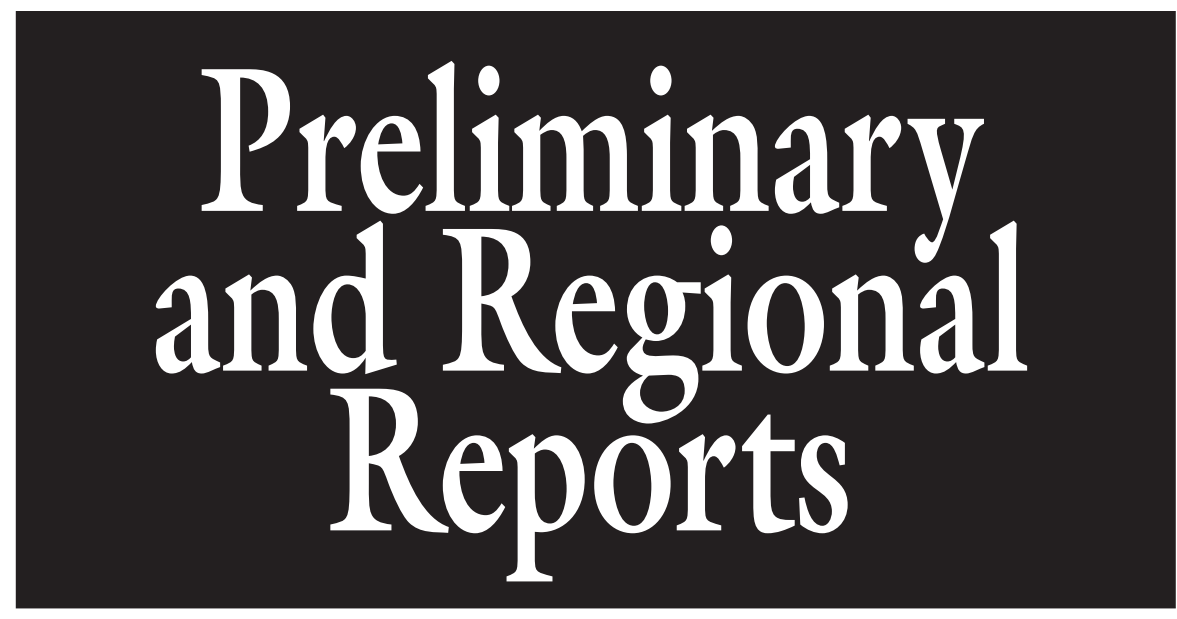

\title{
Refractometer Measurements of Soluble Solid Concentration Do Not Reliably Predict Sugar Content in Sweet Corn
}

\author{
Teri A. Hale, Richard L. Hassell, and Tyron Phillips
}

ADDITIONAL INDEX wORDs. HPLC, maturity, soluble solids, Brix, sucrose, total sugars, sugary, shrunken, sugary enhancer, phenotypes

Summary. The refractometer has been proposed as a rapid, inexpensive technique for determining sugar levels in fresh sweet corn (Zea mays). High performance liquid chromatography (HPLC) analysis of sugars in three phenotypes $(s u, s e$, and $s h_{2}$ ) of sweet corn harvested at three maturities indicated that sucrose content was highly correlated with the total sugars $(R=0.95)$. Sucrose and total sugar concentration were significantly different among all phenotypes. Soluble solids concentration (SSC) was high in $s u$ and $s e$ compared to the lower SSC of $s h_{2}$. Early, mature, and late harvested samples differed in sucrose and total sugar content. Sugar concentration varied within phenotypes at each maturity level. $S h{ }_{2}$ indicated no difference in sucrose and total sugars at early and mature harvests, but increased at late harvest. In contrast, sucrose and total sugar content decreased between early and mature harvests, then increased to highest levels at late harvest in $s e$ and $s u$ phenotypes. Overall, phenotype SSC increased significantly from early to late harvests, probably due to increased water-soluble polysaccharides in the $s u$ and $s e$ cultivars. Unlike other crops, a negative relationship was found in sweet corn between SSC and sucrose or total sugars, with an overall correlation of -0.51 . This relationship was most affected by maturity, especially mature and late harvested sweet corn. Among phenotypes, sucrose, total sugar, and SSC were poorly correlated. Our results indicate that a refractometer should not be used to estimate total sugars or sucrose of sweet corn.

S weet corn is used within the U.S. for fresh consumption, canning, and freezing. The USDA reported that the value of sweet corn has increased $81 \%$ in the last decade, with the fresh market accounting for the majority of the crop value (Lucier and Lin, 2001). The consumption of fresh sweet corn has increased $62 \%$ from a decade ago. The reason for the boost in popularity is the introduction

Clemson University, Coastal Research and Education Center, 2700 Savannah Highway, Charleston, SC 29414 of new phenotypes with enhanced flavor and increased shelf life (Hassell et al., 2003).

The upward trend in production and consumption of sweet corn has led to an increase in research on the sweet corn characteristics that enhance marketability. Sweet corn is divided into three phenotypes: sugary $(s u)$ sugary enhanced $(s e)$, and shrunken-2 $\left(s h_{2}\right)$, with phenotype defined as an organism as observed by its visible characteristics, resulting from the interaction of its genotype with the environment. Two phenotypes currently dominating the marketplace are se and $s h_{2}$. Se produces higher sugar than $s u$ without compromising the level of phytoglycogen, a water-soluble starch contributing to sweet corn creaminess (Ferguson et al., 1978; Gonzales et al., 1976). Sh enhances sugar levels similar to or greater than $s e$; however, unlike $s e$ and $s u$, it does not accumulate phytoglycogen (Brecht et al., 1990; Gonzales et al., 1976). These high sugar phenotypes are less susceptible to sugar loss after harvest and during storage, increasing the length of marketability for fresh sweet corn (Laughman, 1961). Sh shelf life is enhanced due to a slower rate of carbohydrate and moisture loss after harvest than se (Garwood et al., 1976). However, sh has not done well in commercial production due to poor germination and seedling vigor (Lucier and Lin, 2001; Wong et al., 1994).

Although there are differences between $s u, s e$, and $s h$, sweet corn cultivars, the largest factor affecting their marketability is flavor. Food scientists define flavor as the total experience from sweetness, texture, and odor, with sweetness being the most important factor in sweet corn (Flora and Wiley, 1974). Sucrose has been identified as the predominant sugar in sweet corn and is responsible for the sweet perception (Juvik and LaBonte, 1988; Reyes et al., 1982; Wong et al., 1994). Panel evaluations of sweetness in sweet corn have a strong positive correlation of "sweet perception" with HPLC analysis of sucrose and total sugars (Evenson and Boyer, 1986; Reyes et al., 1982; Zhu et al., 1992).

\begin{tabular}{llll}
\hline $\begin{array}{l}\text { Units } \\
\begin{array}{l}\text { To convert U.S. to SI, } \\
\text { multiply by }\end{array}\end{array}$ & U.S. unit & Sl unit & $\begin{array}{l}\text { To convert SI to U.S., } \\
\text { multiply by }\end{array}$ \\
\hline 10 & $\%$ & $\mathrm{mg} \cdot \mathrm{g}^{-1}$ & 0.1 \\
29.5735 & $\mathrm{fl} \mathrm{oz}$ & $\mathrm{mL}$ & 0.0338 \\
0.3048 & $\mathrm{ft}$ & $\mathrm{m}$ & 3.2808 \\
3.7854 & $\mathrm{gal}$ & $\mathrm{L}$ & 0.2642 \\
2.5400 & inch(es) & $\mathrm{cm}$ & 0.3937 \\
28.3495 & $\mathrm{Oz}$ & $\mathrm{g}$ & 0.0353 \\
$\left({ }^{\circ} \mathrm{F}-32\right) \div 1.8$ & ${ }^{\circ} \mathrm{F}$ & ${ }^{\circ} \mathrm{C}$ & $\left(1.8 \times{ }^{\circ} \mathrm{C}\right)+32$
\end{tabular}


The refractometer, which measures SSC, has been utilized as a rapid, preharvest method to determine sweet corn sugar content (Kleinhenz, 2003; Randle et al., 1984; Zhu et al., 1992). In many crops, SSC measures mainly sugars and acids with perhaps some water-soluble cell wall component. This makes the refractometer a good predictor of sucrose content. However, refractometer readings of sweet corn SSC do not appear to follow the high positive correlation of sucrose to SSC found in other crops. Zhu et al. (1992) found that in sweet corn, total sugars (largely sucrose) decreased with increasing SSC. In contrast, Kleinhenz (2003) found that sensory quality and SSC may be positively related, using se and $s h_{2}$ phenotypes. Kleinhenz (2003) cited the work of Zhu et al. (1992) in evaluating sweet corn characteristics in Ohio, stating that relationships between SSC and sensory quality may benefit large-scale cultivar evaluations. Although this study did not examine total sugars, it determined that $s h_{2}$ had lower SSC at maturity and $48 \mathrm{~h}$ after maturity than did se varieties. Some variations in this have been explained as effects of genotype and environment interactions, suggesting caution in using the refractometer as a determination of sugar content in sweet corn. Both Zhu et al. (1992) and Kleinhenz (2003) based their use of the refractometer on the work of Randle et al. (1984), who stated that the refractomer indicated differences in accumulating sugars. All previous studies were done only at one maturity level.

The ultimate goal of our research was to identify a rapid, inexpensive method to estimate sweet corn flavor and acceptability. The specific goal of this work was determine if SSC was correlated to sucrose and total sugar concentration of $s u$, se, and $s h{ }_{2}$ sweet corn at different maturities.

\section{Materials and methods}

A total of nine cultivars of sweet corn were used with three cultivars per phenotype $\left(s u, s e, s h_{2}\right)$. Cultivars were selected using recommendations from seed companies. Su cultivars included 'NK199', 'Golden Cross Bantam', and 'Jubilee' (Rupp Seed, Wauseon, Ohio). Secultivars were 'Precious Gem', 'Brocade', and 'Lancelot' (Mesa Maize, Olathe, Colo.), and $s h_{2}$ cultivars were 'Rustler' and 'Zenith' (Harris Moran, Modesto, Calif.) and 'ACX904' (Ab- bott and Cobb, Feasterville, Pa.). Seeds were counted into 60 seeds/packet per single row using a Contador $\mathrm{E}$ counter (Baumann Saatzuchtbedarf, Waldenburg, Germany). Cultivars were planted in a RCBD on 28 Mar. 2003 and $s u$ and $s h_{2}$ cultivars were replanted 9 May 2003, due to severe bird damage. All phenotypes were isolated by at least $250 \mathrm{ft}$ to prevent cross-pollination. All plots were planted in Younges fine loamy sand at the Clemson University Coastal Research and Education Center (CREC) located in Charleston, S.C. Each cultivar was replicated four times with a plot consisting of four rows, $40 \mathrm{ft}$ long, $3 \mathrm{ft}$ between rows. All plots were seeded with a cone planter (Almaco, Nevada, Iowa) mounted on a John Deere 33 Flex B planter (John Deere, Moline, Ill.). Once the seed germinated and reached 6-8 inches in height, rows were hand-thinned to 8 inches between plants. Plots were watered and fertigated using drip lines, following standard sweet corn practices. Herbicide and pesticide regimens followed recommendations for the southern region (Hassell, 2004).

Harvest. All plots were handharvested at three different maturities. At each maturity, ears were taken at random from within each plot. Based on previous work at the CREC, fullplot maturity was determined to be 19 $\mathrm{d}$ after $100 \%$ silking of all the plants in the plot. Early maturity was defined as $5 \mathrm{~d}$ before maturity or $14 \mathrm{~d}$ after $100 \%$ silking where ears were not filled out to the tip and full kernel color had not been achieved. Late maturity was taken $5 \mathrm{~d}$ after maturity, or $24 \mathrm{~d}$ after $100 \%$ silking, where the ears were completely filled to the tip, colored, and kernel denting had begun. Ten to 15 ears were randomly harvested from each plot at each of the three maturities. The husks were removed and ears were divided into the following categories for analysis: five ears for refractometer measurement, five for HPLC analysis, and the remaining ears used for other analysis.

REFRACTOMETER. Within an hour after harvest, kernels were cut from the center section of five ears from each plot, after a 2 -inch section was removed from each end of each ear. Twenty-five grams from each ear were placed on a double layer $13 \times 13-\mathrm{cm}$ square of cheesecloth (BBA Nonwovens, Walpole, Mass.). Samples were then strained through cheesecloth using a lemon squeezer. Extract was collected and placed on the ABBE Mark II digital refractometer (Reichert Scientific Instruments, Buffalo, N.Y.) for analysis. Two readings per extract were performed and recorded to the nearest 10th for each of the five ears. This procedure was repeated for all plots at all maturities.

HPLC. The ends of five ears per plot were removed using a portable band saw. The remaining cobs were then frozen in liquid nitrogen within $3 \mathrm{~h}$ of harvest, placed in 1 -gal freezer bags, and stored in a deep freezer at -30 ${ }^{\circ} \mathrm{F}$. Kernels were removed from frozen cobs by hitting them with a hammer while in the freezer bags. Kernels were placed into l-qt freezer bags and stored until used for HPLC analysis.

All HPLC sample preparation and analysis were performed in the Poole Agriculture Center at Clemson University, Clemson, S.C. Samples were prepared using modified methods of Zhu et al. (1992). One hundred grams of kernels were homogenized for 2 min in a Waring (Waring, Torrington, Conn.) blender. Two 2-g samples of homogenate were mixed with $4 \mathrm{~mL}$ 80:20 ethanol-water mixture in 15$\mathrm{mL}$ centrifuge tubes, heated in $85^{\circ} \mathrm{C}$ water-bath for $5 \mathrm{~min}$, and centrifuged at $42,000 g_{\mathrm{n}}$ for $10 \mathrm{~min}$. Supernatant was decanted and retained. Precipitate was washed using $4 \mathrm{~mL}$ of ethanol mixture, heated and centrifuged as previously described. Two ethanolwater washings were collected and combined with first supernatant and centrifuged for $10 \mathrm{~min}$.

Sample was filtered using $10-\mathrm{mL}$ poly prep column (Bio-Rad, Richmond, Calif.) prepared with $2 \mathrm{~mL}$ of cation exchange resin (Amberlite IRA 68; Sigma-Aldrich, St. Louis) and 1 $\mathrm{mL}$ of ion-exchange resin (Dowex 50x4-200; Sigma-Aldrich). Columns were washed with $1 \mathrm{~mL}$ of $80: 20$ ethanol-water mixtures before and after 5 $\mathrm{mL}$ of sample were filtered. Ethanol mixture was evaporated at $70{ }^{\circ} \mathrm{C}$ for 50 min using a Rapidvap (Labconco, Kansas City). Evaporated sample was mixed with $10 \mathrm{~mL}$ HPLC-grade water. One milliliter of this mixture was then mixed with $5 \mathrm{~mL}$ of HPLC grade water to be used for HPLC analysis. From this solution, $1.5 \mathrm{~mL}$ was placed into auto sampler vials (Dionex, Sunnyvale, Calif.). Twenty microliters were injected into the $\mathrm{Di}$ onex DX-300 HPLC (AGP-1 pump 
and ASM-3 auto sampler) and sucrose, glucose, and fructose were separated using with a Carbo-Pak PAl column $(4 \times 250 \mathrm{~mm})$ (Dionex) maintained at $85{ }^{\circ} \mathrm{C}$. Sugars were detected with an electrochemical detector (Pulsed Amperometric Detector; Dionex). Data were recorded using PeakNet 5.11 software (Dionex). The mobile phase $(0.2 \mathrm{M} \mathrm{NaOH})$ was previously filtered and degassed. Quantification of individual sugars was determined based on calibration curves obtained from their respective standards. This procedure was followed for each treatment for a total of 108 samples.

Statistical analysis. Data were analyzed as a three-factor design with variety nested in phenotype, and phenotype and maturity being cross-classified. Analysis of variance (ANOVA) was performed on main effects and interactions followed by pair-wise means comparison using a general linear model (SAS v.8; SAS Institute, Cary, N.C.) (Table 1). Refractometer and HPLC data were analyzed using a general linear model (GLM) for determining significance of main effects and interactions. The ANOVA indicated significant interactions of maturity and phenotypes for SSC, sucrose, and total sugars. An interaction of cultivar, sucrose, and total sugars was also found.

\section{Results}

REFRACTOMETER ANALYSIS. Within $s u$, 'Golden Cross Bantam' had $25.7 \%$ SSC, the highest of all cultivars, although that of se cultivar Precious Gem was not significantly lower (Table 2). $S u$ 'NK199' and 'Jubilee' were not significantly different in SSC from all three se cultivars. $S h_{2}$ had the lowest SSC of the three phenotypes. Variations in phenotypes according to maturity indicated that at early maturity, se and $s u$ were not significantly different in SSC from early $s h_{2}$ samples (Table 3 ). $\mathrm{Su}$ and se SSC continued to increase an additional $10.6 \%$ and $8.8 \%$, respectively, with maturity. However, $s h_{2}$ SSC remained low and constant at all three harvest periods.

HPLC ANALYSIs. When pooled over maturities, all $s u$ and se cultivars within phenotype had similar sucrose content (Table 2). The $s h_{2}$ cultivar Rustler was lower in sucrose than 'Zenith' or 'ACX904,' but still had significantly more sucrose than $s u$ or se cultivars. Sucrose levels were significantly higher
Table 1. Sources of variation in the analysis of variance (ANOVA) for early, mature, and late harvested sugary, sugary enhancer, and shrunken-2 sweet corn for soluble solid concentration (SSC) and high-performance liquid chromatography (HPLC) analysis of sucrose and total sugars.

\begin{tabular}{lccc}
\hline & \multicolumn{2}{c}{ Proportion of total sums of squares $(\%)^{\mathrm{z}}$} \\
\cline { 2 - 4 } Source of variation & \multicolumn{2}{c}{ HPLC analysis } & SSC \\
\cline { 2 - 4 } & Sucrose & Total sugars & $40^{*}$ \\
Phenotype (P) & $35^{*}$ & $56^{*}$ & 3 \\
Replication (R) & 3 & 4 & $4^{*}$ \\
Cultivar (phenotype) (C) & $6^{*}$ & $7^{*}$ & 4 \\
R $\times$ C & 2 & 3 & $19^{*}$ \\
Maturity (M) & $7^{*}$ & $9^{*}$ & $14^{*}$ \\
M $\times$ P & $4^{*}$ & $3^{*}$ & 4 \\
M $\times$ C & $4^{*}$ & $6^{*}$ & 12 \\
Error & 9 & 12 & 0.88 \\
$\mathrm{R}^{2}$ & 0.91 & 0.88 & 13.80 \\
CV & 22.35 & 18.40 & .
\end{tabular}

${ }^{2}$ The sum of squares for each of the factors in the ANOVA have been converted to percentages of the total sum of squares.

${ }^{*}$ F values significant at $P=0.05$

Table 2. Cultivar main effect for soluble solids concentration (SSC) and highperformance liquid chromatography (HPLC) analysis of sucrose and total sugars in nine cultivars of sweet corn, pooled over maturities.

\begin{tabular}{lllcl}
\hline \multirow{2}{*}{ Phenotype } & \multicolumn{1}{c}{ Cultivar } & \multicolumn{3}{c}{ HPLC analysis $\left(\mathbf{m g}^{-\mathbf{1}}\right)^{\mathrm{z}}$} \\
\cline { 3 - 5 } Sugary $(\mathrm{su})$ & NK199 & $4.00 \mathrm{~d}-\mathrm{f}^{\mathrm{x}}$ & $8.22 \mathrm{c}$ & $22.1 \mathrm{~b}$ \\
& Golden Cross Bantam & $3.67 \mathrm{f}$ & $5.82 \mathrm{e}$ & $25.7 \mathrm{a}$ \\
& Jubilee & $3.85 \mathrm{ef}$ & $6.76 \mathrm{de}$ & $22.0 \mathrm{~b}$ \\
Sugary enhancer $(s e))$ & Brocade & $4.96 \mathrm{~cd}$ & $7.77 \mathrm{~cd}$ & $21.8 \mathrm{~b}$ \\
& Precious Gem & $5.58 \mathrm{c}$ & $8.62 \mathrm{c}$ & $23.6 \mathrm{ab}$ \\
& Lancelot & $4.66 \mathrm{c}-\mathrm{e}$ & $7.46 \mathrm{~cd}$ & $23.2 \mathrm{~b}$ \\
Shrunken-2 $\left(\right.$ sh $\left._{2}\right)$ & Rustler & $8.17 \mathrm{~b}$ & $11.24 \mathrm{~b}$ & $15.0 \mathrm{c}$ \\
& Zenith & $10.44 \mathrm{a}$ & $13.52 \mathrm{a}$ & $14.7 \mathrm{c}$ \\
& ACX904 & $11.16 \mathrm{a}$ & $14.08 \mathrm{a}$ & $15.4 \mathrm{c}$ \\
\hline
\end{tabular}

${ }^{2}$ Sucrose and total sugars determined on fresh weight basis $\left(1 \mathrm{mg} \cdot \mathrm{g}^{-1}=1000 \mathrm{ppm}\right)$.

Total sugar is sum of glucose, fructose, and sucrose.

${ }^{x}$ Means separated within columns using $t$ test least square means separation test at $P \leq 0.05$.

Table 3. Interaction of sweet corn maturity levels and phenotypes on sugar levels and soluble solids concentration (SSC), cultivar response pooled.

\begin{tabular}{lccc}
\hline & \multicolumn{3}{c}{ Sugar levels $\left(\mathbf{m g}^{-1}\right)^{\mathrm{z}}$} \\
\cline { 2 - 4 } & Sucrose & Total sugars $^{\mathrm{y}}$ & SSC (\%) \\
\hline Sugary (su) & & \\
$\quad$ Early & & & \\
Mature & $3.99 \mathrm{de}$ & $7.02 \mathrm{de}$ & $17.6 \mathrm{~cd}$ \\
Late & $3.00 \mathrm{e}$ & $6.32 \mathrm{e}$ & $24.0 \mathrm{~b}$ \\
Sugary enhancer (se) & $4.52 \mathrm{~cd}$ & $7.46 \mathrm{de}$ & $28.2 \mathrm{a}$ \\
$\quad$ & & \\
Early & $5.41 \mathrm{c}$ & $8.54 \mathrm{~cd}$ & $18.0 \mathrm{c}$ \\
Mature & $4.12 \mathrm{de}$ & $6.14 \mathrm{e}$ & $23.8 \mathrm{~b}$ \\
Late & $5.66 \mathrm{c}$ & $9.17 \mathrm{c}$ & $26.9 \mathrm{a}$ \\
Shrunken-2 (sh $\left.{ }_{2}\right)$ & & & \\
Early & $8.63 \mathrm{~b}$ & $12.19 \mathrm{~b}$ & $15.8 \mathrm{ce}$ \\
Mature & $8.87 \mathrm{~b}$ & $11.50 \mathrm{~b}$ & $15.7 \mathrm{de}$ \\
Late & $12.28 \mathrm{a}$ & $15.14 \mathrm{a}$ & $14.5 \mathrm{e}$ \\
\hline
\end{tabular}

${ }^{\mathrm{z}}$ Sucrose and total sugar determined by high performance liquid chromatography on fresh weight $\left(1 \mathrm{mg} \cdot \mathrm{g}^{-1}=\right.$ $1000 \mathrm{ppm}$ ).

yTotal sugars is the sum of glucose, fructose and sucrose.

${ }^{x}$ Maturity determined by number of days after $100 \%$ silking; early $=14 \mathrm{~d}$; mature $=19 \mathrm{~d}$; late $=24 \mathrm{~d}$.

"Means within columns and main effects separated using $t$ test least square means separation test at $P \leq 0.05$. 
at early harvest of the se cultivar Precious Gem $\left(7.14 \mathrm{mg} \cdot \mathrm{g}^{-1}\right)$ compared to 'Brocade' $\left(4.54 \mathrm{mg} \cdot \mathrm{g}^{-1}\right)$ and 'Lancelot' $\left(4.54 \mathrm{mg} \cdot \mathrm{g}^{-1}\right)$; however, 'Precious Gem' $\left(5.21 \mathrm{mg} \cdot \mathrm{g}^{-1}\right)$ levels decreased with maturity, while the 'Brocade' and 'Lancelot' (6.09 and $5.68 \mathrm{mg} \cdot \mathrm{g}^{-1}$, respectfully) cultivars increased with late harvests. In contrast, $s h_{2}$ remained constant at early and mature harvest and was the highest of all three phenotypes by late harvest (Table 3 ). All phenotypes had the highest sucrose concentrations at late harvest. Seand su had lower sucrose than $s h{ }_{2}$ at all harvest dates. $S u$ and se phenotypes decreased in sucrose at maturity, while late harvest sucrose levels increased to be similar to early harvest levels.

Correlations. Strong overall correlations were seen with maturity, sucrose, and total sugar concentration (Table 4). Sucrose to SSC yielded an overall $\mathrm{r}$ of $-0.5 \mathrm{l}$, primarily due to maturity effects rather than phenotype effects. The strongest relationships of SSC to sucrose and SSC to total sugar concentration were seen between mature and late harvested sweet corn, although all relationships were negatively correlated. Overall, sucrose and total sugar concentration were strongly correlated $(r=0.96)$.

\section{Discussion}

Sucrose concentrations can be used as characteristic of both overall phenotype, especially between $s u$ and $s h_{2} . S h_{2}$ demonstrated higher levels of sucrose at all maturities than either $s u$ or se. The decrease in sucrose concentration in $s u$ and $s e$ at maturity may be attributed to the reduction of sucrose to glucose and fructose. The increase of sucrose from mature harvest to late harvest is attributed to sucrose's role as an intermediate to starch formation in overripe sweet corn. The low water-soluble polysaccharide (WSP) concentration of $s h_{2}$ compared to $s e$ and $s u$ is the cause for $s h_{2}$ consistency in sucrose at early and mature harvests (Garwood et al., 1976).

Sucrose accounts for $64 \%$ of the total sugar concentration in se, $55 \%$ in $s u$, and $77 \%$ in $s h$, thus explaining the strong positive relationship of sucrose and total sugars. Similar total sugar concentrations in $s u$ and $s e$ are attributed to the fact that these phenotypes contain higher WSP levels compared to $s_{2}$ (Garwood et al., 1976).

When averaged over maturities and phenotypes, SSC did not correctly separate suand sesugars, indicating that refractometer measurements were not a good indicator of phenotype differences. Although the refractometer better determined phenotypic difference at a late harvest, it has no value for field use, as late harvested sweet corn is too tough in texture for consumers (Hale et al., 2004). Sucrose and total sugar concentration were not well enough correlated to SSC to make the refractometer useful for estimating sugars.

Zhu et al. (1992) and Kleinhenz (2003) stated that the refractometer may be used as a rapid field test for determining sugar content in sweet corn. Zhu et al. (1992) reported an overall $\mathrm{r}$ of -0.99 between SSC and total sugars. Kleinhenz suggested the refractometer as a reliable estimation of kernel sucrose in $s e$ and $s h_{2}$ phenotypes. Zhu etal. (1992) and Kleinhenz (2003) based their use of the refractometer on the work of Randle et al. (1984), who stated that SSC changes were indicative of differences in accumulating sugars. However, this work did not explain how the relationship between SSC and sugar content was determined. Our data indicated that the refractometer cannot be used as a reliable indicator of sweet corn sucrose and total sugar concentrations. The negative overall correlations between SSC and HPLC-analyzed sugars suggest that as

Table 4. Correlation matrix of soluble solid concentrations (SSC) with sucrose and total sugars in nine cultivars of sweet corn.

\begin{tabular}{|c|c|c|c|c|c|c|c|}
\hline \multirow[b]{2}{*}{ Relationship } & \multirow[b]{2}{*}{ Overall $^{\mathrm{z}}$} & \multicolumn{3}{|c|}{ Phenotype } & \multicolumn{3}{|c|}{ Maturity $^{\mathrm{x}}$} \\
\hline & & $s u$ & se & $s h_{2}$ & Early & Mature & Late \\
\hline SSC to sucrose $\mathrm{z}^{\mathrm{z}}$ & -0.51 * & 0.24 & -0.15 & -0.17 & -0.32 * & -0.67 * & $-0.76^{*}$ \\
\hline SSC to total sugars & $-0.51^{*}$ & -0.01 & -0.15 & -0.19 & $-0.40^{*}$ & $-0.72 *$ & $-0.73^{*}$ \\
\hline Sucrose to total sugars & $0.96^{*}$ & $0.68^{*}$ & $0.97^{*}$ & $0.98^{*}$ & $0.98^{*}$ & $0.94^{*}$ & 0.98 * \\
\hline
\end{tabular}

SSC increased, sucrose or total sugars decreased. This is contrary to work with the refractometer in other fruit and vegetables such as watermelon (Citrullus vulgaris), grapes (Vitis spp.), apples (Malus $\times$ domestica), and strawberries (Fragaria $\times$ ananassa), in which as sucrose levels increase, SSC levels also increase (Harker et al., 2002; Pardo etal., 1997; Qudsieh etal., 2001; Sonego et al., 2002; Wang, 2000). This negative relationship of sucrose and SSC in sweet corn indicated that the refractometer is detecting more than sugars in sweet corn, especially with later maturities. The increased SSC measurements may be attributed to increased WSP with maturity. Both $s e$ and $s u$ cultivars, which are higher in WSP (Garwood et al., 1976), increased in SSC with increased maturity, while $s h_{2}$ contains lower WSP and remained constant.

\section{Literature cited}

Brecht, J.K., S.A. Sargent, R.C. Hochmuth, and R.S. Tervola. 1990. Postharvest quality of supersweet (sh2) sweet corn cultivars. Proc. Fla. State Hort. Soc. 103:283-287.

Evenson, K.B. and C.D. Boyer. 1986. Carbohydrate composition and sensory quality of fresh and stored sweet corn. J. Amer. Soc. Hort. Sci. 111:734-738.

Ferguson, J.E., A.M. Rhodes, and D.B. Dickinson. 1978. Genetics of sugary enhancer $(s e)$ an independent modifier of sweet corn (su). J. Hered. 69:377-380.

Flora, L.F. and R.C. Wiley. 1974. Sweet corn aroma, chemical components and relative importance in the overall flavor response. J. Food Sci. 39:770-773.

Garwood, D.L., F.J. McArdle, S.F. Vanderslice, and J.C. Shannon. 1976. Postharvest carbohydrate transformations and processed quality of high sugar maize genotypes. J. Amer. Soc. Hort. Sci. 101:400-404.

Gonzales, J.W., A.M. Rhodes, and D.B. Dickinson. 1976. Carbohydrates and enzymatic characterization of a high sucrose sugary inbred line of sweet corn. Plant Physiol. 58:28-32.

Hale, T.A., R.L. Hassell, T. Phillips, and E. Halpin. 2004. Panel perception of pericarp tenderness in su, se, and $\mathrm{sh}_{2}$ sweet corn at three maturities. HortTechnology $14: 521-524$

Hassell, R.L., R.J. Dufault, and T. Phillips. 2003. Low-temperature germination response of su, se, and sh, sweet corn cultivars. HortTechnology 13:136-141.

Hassell, R.L. 2004. Sweet corn, p. 67-69. In: D.C. Sanders (ed.). Vegetable crop guide- 
lines for the southeastern U.S. 2004-2005. Helena Chemical Co., Memphis, Tenn.

Harker, F.R., K.B. Marsh, H. Young, S.H. Murray, F.A. Gunson, and S.B. Walker. 2002. Sensory interpretation of instrumental measurements 2: Sweet and acid taste of apple fruit. Postharvest Biol. Technol. 24:241-250.

Juvik, J.A. and D.R. LaBonte. 1988. Single kernel analysis for the presence of the sugary enhancer (se) gene in sweet corn. HortScience 23:384-386.

Kleinhenz, M.D. 2003. Sweet corn variety trials in Ohio: Recent top performers and suggestions for future evaluation. HortTechnology 13:711-718.

Laughman, J.R. 1961. Super sweet, a product of mutation breeding in corn. Seed World 13 Jan.:18.

Lucier, G. and B. Lin. 2001. Commodity spotlight. How sweet it is: Fresh sweet corn. Agriculture Outlook. 7 June 2004. $<$ www.ers.usda.gov/publications/AgOutlook/Aug2001>.

Randle, W.M., D.W. Davis, and J.V. Groth. 1984. The effects of corn leaf rust on maturity and quality of fresh market ears of sweet corn. J. Amer. Soc. Hort. Sci. 109:654-648.

Pardo, J.E., R. Gomez, J.T Ardaguila, M. Amo, and R. Varon. 1997. Quality evaluation of watermelon varieties (Citrullus vulgaris S.). J. Food Quality 20:547-557.

Qudsieh, H.M., S. Yusof,A. Osman and R.A. Rahman. 2001. Physico-chemical changes in sugarcane (Sacharum officinarum var yellow cane) and the extracted juice at different portions of the stem during development and maturation. Food Chem. 75:131-137.

Reyes, F.G.R., G.W. Varseveld, and M.C. Kuhn. 1982. Sugar composition and flavor quality of high sugar (shrunken) and normal sweet corn. J. Food Sci. 47:753-755.

Sonego, L., S. Lurie, Y. Zuthi, T. Kaplonov, R. Ben-Arie, and I. Kosto. 2002. Factors affecting taste scores of early season seedless table grape cv. Mystery and Prime. J. Agr. Food Chem. 50:544-548.

Wang, C.Y. 2000. Effect of moist hot air treatment on some postharvest quality attributes of strawberries. J. Food Quality 23:51-59.

Wong, A.D., J.A. Juvik, D.C. Breeden, and J.M. Swiader. 1994. Shrunken 2 sweet corn yield and the chemical components of quality. J. Amer. Soc. Hort. Sci. 119:747-755.

Zhu, S., J.R. Mount, and J.L. Collins. 1992. Sugar and soluble solid changes in refrigerated sweet corn (Zea mays L). J. Food Sci. 57:454-457. 